EESTI NSV TEADUSTE AKADEEMIA TOIMETISED. XV KÖIDE FOUSIKA-MATEMAATIKA- JA TEHNIKATEADUSTE SEERIA, 1966, NR. 2

ИЗВЕСТИЯ АКАДЕМИИ НАУК ЭСТОНСКОН ССР. ТОМ ХV

СЕРИЯ ФИЗИКО-МАТЕМАТИЧЕСКИХ И ТЕХНИЧЕСКИХ НАУК. 1966, № 2

Х. РАУДЕ, С. РАНГ, О. ЭЙЗЕН

\title{
О СОСТАВЕ НЕНАСЫЩЕННЫХ УГЛЕВОДОРОДОВ СРЕДНИХ ФРАКЦИИ ТУННЕЛЬНОЙ СМОЛЫ
}

Настоящее исследование представляет собой продолжение и дополнение наших ранее опубликованных работ $[1-3]$.

Олефины, выделенные из суммарной туннельной смолы методом жидкостно-адсорбционной хроматографии, ректифицировались на узкие фракции (табл. 1). Қак показывают данные жидкостно-адсорбционной хроматографии, олефины составляют $26,7 \%$ туннельной смолы, кипящей в пределах $200-300^{\circ}$ C. Наибольший интерес представляет определение содержания олефинов с прямой алкильной цепью. Присутствующие во фракциях изомерные $н$-олефины можно определить суммарно путем гидрирования их в соответствующие нормальные парафины. Другим способом определения содержания нормальных углеводородов является их селективная адсорбция на молекулярных ситах СаА, использованная нами ранее для определения нормальных парафинов туннельной смолы. [1].

Таблица 1

Результаты ректификации олефинов туннельной смолы и физико-химические показатели полученных фракций

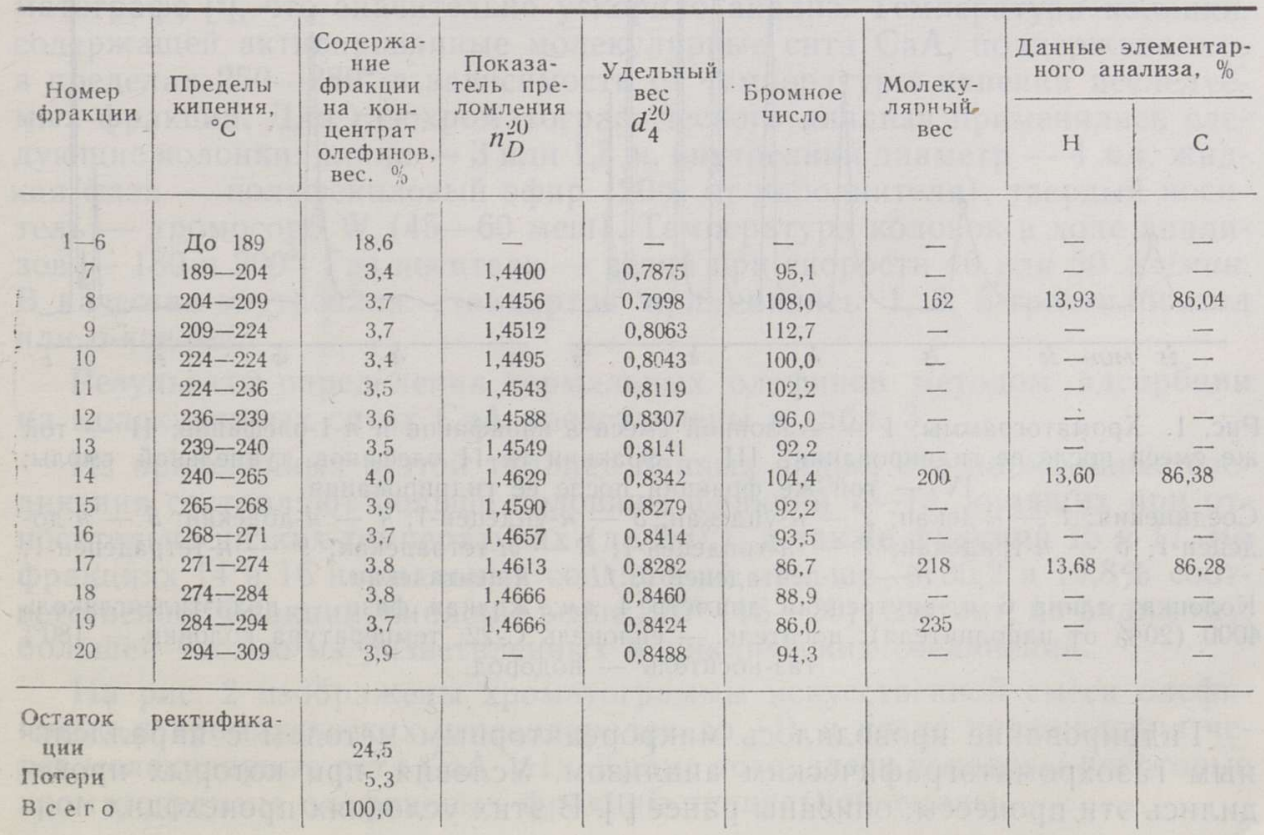




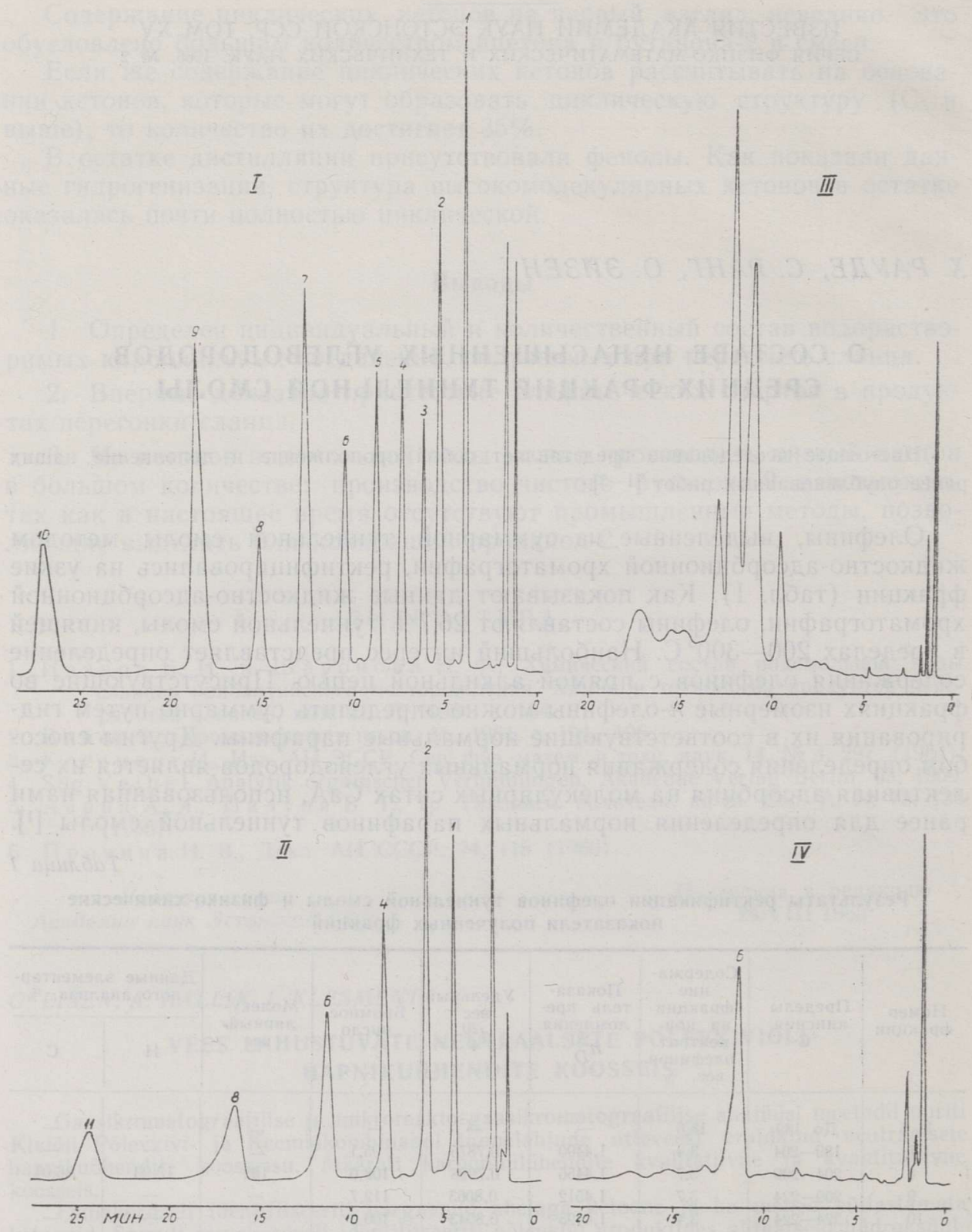

Рис. 1. Хроматограммы: I - эталонной смеси $\boldsymbol{н}$-парафинов и $\boldsymbol{H}$-1-олефннов; II - той же смеси после ее гидрирования; III - фракции № 11 олефинов туннельной смолы; $\mathrm{IV}$ - той же фракции после ее гидрирования.

Соединения: 1 - н-декан; 2 - н-ундекан; $3-$-ундецен-1; 4 - н-додекан; $5-$-додецен-1; 6 - н-тридекан; 7 - н-тридецен-1; 8 - -тетрадекан; 9 - н-тетрадецен-1; 10 - н-пентадецен-1; 11 - н-пентадекан.

Колонка: длина 6 м, внутренний диаметр 4 мм; жидкая фаза - полиэтиленгликоль 4000 (20\% от наполнителя); носитель - силоцель С-22; температура колонки - $180^{\circ}$; газ-носитель - водород.

Гидрирование проводилось микрореакторным методом с параллельным газохроматографическим анализом. Условия, при которых проводились эти процессы, описаны ранее [1]. В этих условиях происходил пол- 
Содержание нормальных олефинов в туннельной смоле по данным гидрирования

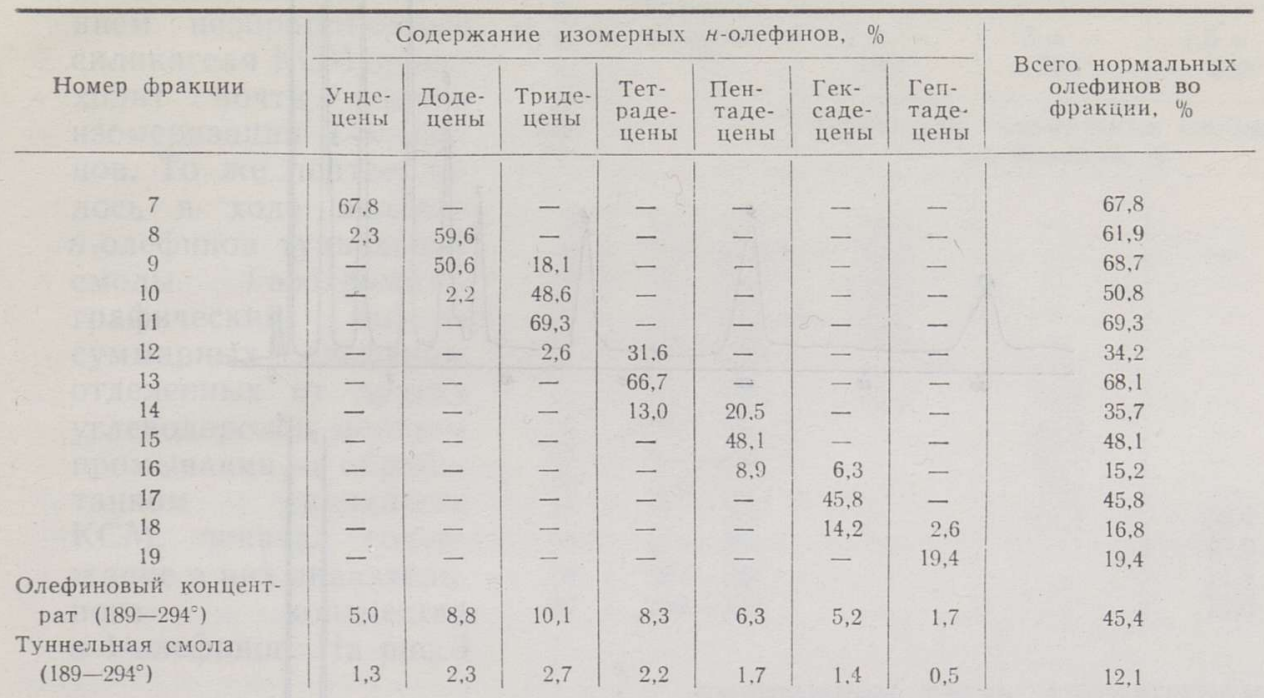

ный переход эталонных нормальных 1-олефинов в нормальные парафины с тем же числом С-атомов в прямой цепи. Иллюстрацией этого является рис. 1. Результаты гидрирования олефиновых фракций туннельной смолы представлены в табл. 2, где приведены данные о содержании изомерных н-олефинов в узких фракциях, в олефинах и смоле, кипящих в пределах $189-294^{\circ}$.

В отличие от нормальных парафинов [1], определение нормальных олефинов при помощи молекулярных сит проводилось на газовом хроматографе [4], что значительно ускорило анализ. Температура колонки, содержащей активированные молекулярные сита СaА, поддерживалась в пределах 250 - $280^{\circ}$ в зависимости от температуры кипения исследуемых фракций. Для газохроматографического анализа применялись следующие колонки: длина -3 или 1,5 м, внутренний диаметр - 4 мм, жидкая фаза - полифениловый эфир (20\% от наполнителя), твердый носитель - хромосорб W (45-60 меш). Температура колонок в ходе анализов - 180 и 200 . Газ-носитель - гелий при скорости 40 или $50 \mathrm{M} / / \mathrm{Muн}$. В качестве внутренних стандартов применялись 1, 3, 5-триэтилбензол или $о$-ксилол.

Результаты определения нормальных олефинов методом адсорбции на молекулярных ситах СаА представлены в табл. 3.

Из приведенных в этой таблице данных видно, что нормальные соединения составляют больше половины фракций $7-13$, кипящих при относительно низких температурах (до $240^{\circ}$ ), а также фракций 15 и 17 . Во фракциях 14 и 16 нормальных соединений меньше - 36,2 и 19,8\% соответственно. Фракции, кипящие выше $275^{\circ}$ (18-20), состоят, по-видимому, большей частью из разветвленных и циклических соединений.

На рис. 2 изображены хроматограммы искусственной смеси олефиновых и ароматических углеводородов до (I) и после прохождения через молекулярные сита СаА (II). Кроме того, здесь показаны некоторые хроматограммы олефиновых фракций туннельной смолы. 

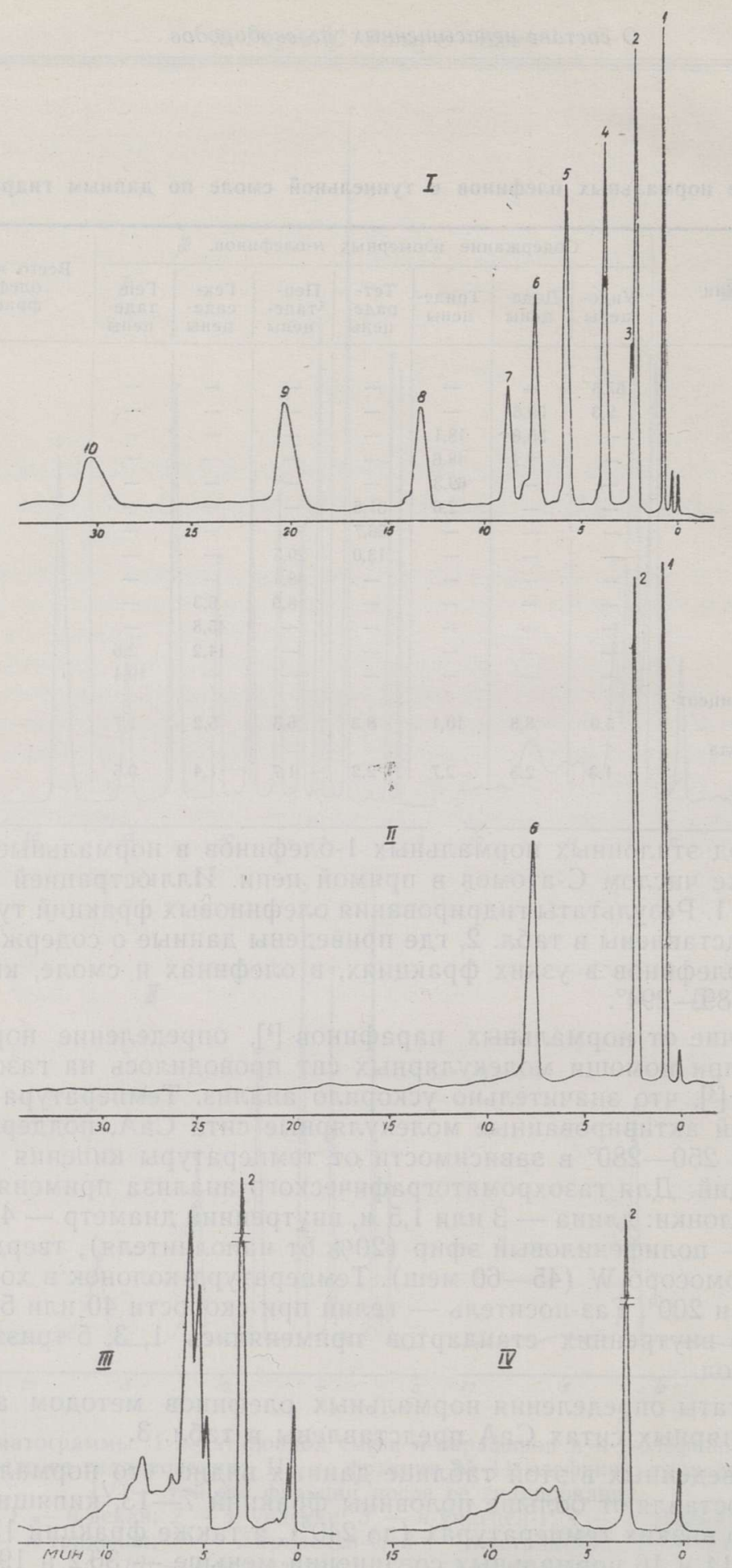

Рис. 2. Хроматограммы: I - эталонной смеси $\boldsymbol{H}$-1-олефинов и ароматических углеводородов; II - той же смеси после прохождения ее через молекулярные сита СаA; III олефнновой фракции № 9 туннельной смолы; IV - той же фракции после прохождения ее через молекулярные сита СаA.

Соединения: 1 - бензол; 2 - о-ксилол; 3 - н-ундецен- $1 ; 4-\mu$-додецен-1; 5 -

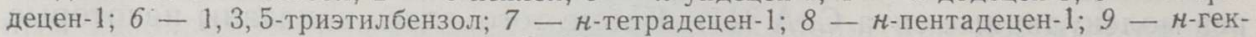
садецен-1; $10-\boldsymbol{H}$-гептадецен- 1.

Колонка: длина 3 м, внутренний диаметр 4 мм; жидкая фаза - полифениловый эфир (20\% от наполнителя); носитель - хромосорб $\mathrm{W}$; температура колонки - $180-200^{2}$; газ-носитель - гелий. 
Наибольший интерес представляет вопрос о содержании н-1-олефинов. Специальные исследования [5] показали, что под влиянием необработанного силикагеля КСМ происходит почти полная изомеризация 1-олефинов. То же подтвердилось в ходе анализа н-олефинов туннельной смолы. Газохроматографический анализ суммарных олефинов, отделенных от других углеводородов методом промывания на обработанном силикагеле KCM, показал содержание в них значительного количества н-1-олефинов. На рис. 3
Содержание нормальных соединений в олефиновых фракциях туннельной смолы по данным адсорбции на молекулярных ситах СаА

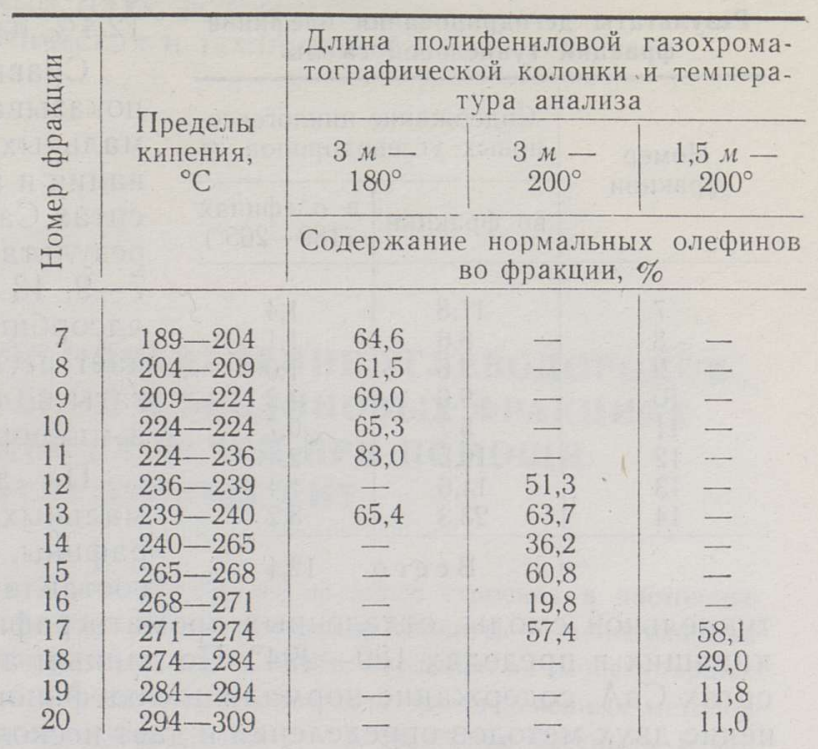

изображены часть хроматограммы олефинового концентрата, полученного на обработанном силикагеле (I), и хроматограмма олефинов туннельной смолы, отделенных промыванием на необработанном силикагеле марки КСМ (II). На второй хроматограмме отсутствуют высокие пики $\mu$-1-олефинов. Результаты исследования узких фракций олефинов подтвердили вышесказанное.

Для определения содержания циклогексеновых углеводородов в исследуемых фракциях пользовались методом микрореакторного дегидрирования вместе с газохроматографическим анализом, по ранее описанной методике [1]. Результаты дегидрирования узких фракций $7-$ 14 (пределы кипения от 189 до 265) приведены в табл. 4.

Из представленных в табл. 4 данных видно, что содержание циклогексеновых углеводородов в исследованных фракциях составляет от 5,7 до 23,3\% всей фракции. Кипяшая в пределах $189-265^{\circ}$ часть оле-

Рис. 3. Часть хроматограммы олефинов туннельной смолы: I - отделенных на обработанном силикагеле КСМ; II - отделенных на необработанном силикагеле КСМ. Соединения: 1 - н-додецен-1; 2 - $н$-тридецен- $1 ; 3-н$-тетрадецен- 1 .

Колонка и условия хроматографирования те же, что на рис. 1 . 
Таблицца 4

Результаты дегидрирования олефинов фракций туннельной смолы

\begin{tabular}{c|c|c}
\hline \multirow{2}{*}{$\begin{array}{c}\text { Номер } \\
\text { фракции }\end{array}$} & \multicolumn{2}{|c}{$\begin{array}{c}\text { Содержание циклогексе- } \\
\text { новых углеводородов, \% }\end{array}$} \\
\cline { 2 - 3 } & во фракции & $\begin{array}{c}\text { в олефинах } \\
\left(189-265^{\circ}\right)\end{array}$ \\
\hline & 11,8 & 1,4 \\
7 & 8,6 & 1,1 \\
8 & 7,6 & 1,0 \\
9 & 9,6 & 1,2 \\
10 & 5,7 & 0,7 \\
11 & 19,5 & 2,4 \\
13 & 11,6 & 1,4 \\
14 & 23,3 & 3,2 \\
\hline & В с е г о & 12,4 \\
\hline
\end{tabular}

финов туннельной смолы состоит на $12,4 \%$ из циклогексенов.

Сравнение данных в табл. 2 іл 3 показывает, что определение нормальных олефинов методом гидрирования и адсорбции на молекулярных ситах $\mathrm{CaA}$ дает, в основном, близкие результаты, особенно во фракциях 7-9, 13 н 14. В остальных случаях адсорбция на молекулярных ситах дает несколько завышенные результаты по сравнению с гидрированием в микрореакторе.

По данным гидрирования нормальных олефинов в нормальные парафины, неразветвленные олефины составляют $45,5 \%$ всех олефинов туннельной смолы, отделенных хроматографированием на силикагеле и кипящих в пределах $189-294^{\circ}$. По данным адсорбции на молекулярных ситах $\mathrm{CaA}$, содержание нормальных олефинов равно $51,5 \%$. Хотя применение двух методов определения и дает несколько различные результаты, можно все же с уверенностью сказать, что олефины с нормальной алкильной цепью представляют собой главную группу в исследуемой области олефинов туннельной смолы.

\section{ЛИТЕРАТ У Р А}

1. Р а уде Х., Эй зе н О., Изв. АН ЭССР. Сер. физ.-матем. и техн. наук, 14, № 4, $614-622(1965)$.

2. Эй зе н О., Р а уд е Х., Изв. АН ЭССР. Сер. физ.-матем. и техн. наук, 14, № 4, $623-630$ (1965).

3. Эй 3 ен О., Р ауд е Х., Изв. АН ЭССР. Сер. физ.-матем. и техн. наук, 14, № 4, $631-634(1965)$.

4. Р анг С., Эй з ен О., К унин г а с К., В яникв е р М., Изв. АН ЭССР. Сер. физ.матем. и техн, наук, 15 , № 3 (в печати).

5. Эй зен О., Куд ря в пе в а Л., Р анг С., Изв. АН ЭССР. Сер. физ.-матем. и техн. наук, 13, № 4, 275-284 (1964).

Ннститут химии

Академии наук Әстонской ССР
Поступила в редакцию 23/XII 1965

\section{H. RAUDE, S, RANG, O. EISEN}

\section{TUNNELAHJUOLI KESKMISTE FRAKTSIOONIDE KÜLLASTUMATA SÜSIVESINIKE KOOSTISEST}

Küllastumata süsivesinikud eraldati tunnelahjuõlist silikageelil kromatografeerimise teel ning rektifitseeriti kitsasteks fraktsioonideks. Normaalsete süsivesinike sisaldus 189-294 ${ }^{\circ} \mathrm{C}$ keevas piirkonnas määrati kahel meetodil: 1) hüdrogeenimise teel mikroreaktorimeetodil koos gaasikromatograafilise analüüsiga, 2) molekulaarsöelte (mark CaA) abil gaasikromatograafilisel meetodil.

\section{H. RAUDE, S. RANG, O. EISEN}

\section{THE COMPOSITION OF UNSATURATED HYDROCARBONS IN MIDDLE FRACTIONS OF SHALE-OIL}

Unsaturated hydrocarbons, separated from shale-oil by means of chromatography with silica, were fractionated in a distillation apparatus. Hydrogenation in a microreactor and sorption in $\mathrm{CaA}$ molecular sieves in a gas-chromatographic apparatus were used to determine normal olefins in fractions boiling between $189-294^{\circ} \mathrm{C}$. 